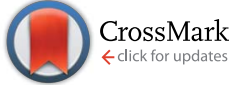

Cite this: J. Mater. Chem. A, 2015, 3, 16354

Received 22nd April 2015

Accepted 7th July 2015

DOI: $10.1039 / c 5 t a 02949 j$

www.rsc.org/MaterialsA

\title{
Carbon dot reduced bimetallic nanoparticles: size and surface plasmon resonance tunability for enhanced catalytic applications $\dagger$
}

\author{
Jeremy B. Essner, Charles H. Laber and Gary A. Baker* \\ We report on a simple and green route toward monometallic (Au or Ag) and alloyed bimetallic AuAg \\ nanoparticles using citric acid-derived carbon nanodots ( $C$-dots) as the reducing and stabilizing agent. \\ Simple variation in the initial $\mathrm{C}$-dot : metal ratio yields a smoothly tunable surface plasmon resonance \\ and the resulting nanomaterials show excellent catalytic activity for 4-nitrophenol reduction which is \\ fully preserved following 5 months of storage. The AuaC-dot catalyst further demonstrated intrinsic \\ peroxidase activity.
}

Metal nanoparticles, especially $\mathrm{Au}$ and $\mathrm{Ag}$, have received increasing attention in recent years owing to their attractive electronic, thermal, optical, and chemical properties, making them applicable in a wide range of fields such as catalysis, biomedicine, photovoltaics, antimicrobials, and surfaceenhanced Raman spectroscopy (SERS). ${ }^{1-6}$ In particular, their properties are greatly influenced by the size, shape, crystal structure, and composition of the monometallic nanoparticles (hereafter, referred to as MNPs), which also dictate how the particles interact with incident light. When the size of the nanoparticle is substantially smaller than the wavelength of incident light, it experiences a relatively uniform electric field, resulting in a collective oscillation of conduction electrons. This gives rise to an energy-dependant resonance known as the surface plasmon resonance (SPR). The optoelectronic properties of the MNPs can be altered or enhanced by incorporating other metals into their structure or by the formation of composites or heterostructures. Indeed, bimetallic NPs (BMNPs) have shown enhanced properties over their monometallic counterparts because of a synergetic coupling between the individual metals' SPRs. ${ }^{7-9}$ The addition of this second metal can improve the electronic and absorption properties, giving rise to SPR bands lying intermediate between the individual MNP SPRs, thereby enhancing photovoltaic, catalytic, and antimicrobial prospects for the material. Recently, Haldar et al. reported on the synthesis of Au@Ag bimetallic core-shell NPs with varying Au core diameters. ${ }^{8}$ These researchers showed that the catalytic efficiency toward the reduction of 4-nitrophenol (4-NP) varied with the Au core size, however, the bimetallic core-shell NPs were still up to 12 times more active than their monometallic $\mathrm{Au}$

Department of Chemistry, University of Missouri-Columbia, Columbia, MO 65211, USA.E-mail: bakergar@missouri.edu

$\dagger$ Electronic supplementary information (ESI) available: Supporting figures and full experimental details. See DOI: 10.1039/c5ta02949j counterparts. In similar vein, our group recently demonstrated a green, sunlight-assisted approach toward the generation of bimetallic AgAu alloys decorated onto 3-aminopropyl-functionalized magnesium phyllosilicate nanoclay sheets. ${ }^{9}$ In this work, the bimetallic-decorated aminoclays possessed superior catalytic and antibacterial activity compared to their pure $\mathrm{Ag}$ or Au NP decorated analogues.

Historically, approaches such as laser ablation ${ }^{10}$ and chemical reduction (e.g., $\mathrm{NaBH}_{4},{ }^{11,12}$ hydrazine ${ }^{13}$ ) were commonly employed to generate MNPs but these methods required either timely, complex, resource-limited equipment, or hazardous chemicals to carry out the reduction. This scenario impelled researchers to shift toward simple, environmentally-friendly, and cost-effective approaches for synthesizing various MNPs, including consideration of phytochemicals found in plant and fruit extracts as the reducing and stabilizing agents. ${ }^{14-23}$ For example, Nadagouda et al. presented a greener synthetic approach for generating both Au and Ag NPs using blackberry, blueberry, pomegranate, and turmeric extracts, taking advantage of the electron donating capabilities of the antioxidants present in the extracts. ${ }^{18}$ Use of these greener reducing agents has also recently been extended to the formation of bimetallic AuAg NPs. For example, Kumari et al. used pomegranate juice to generate both alloyed and core-shell AuAg NPs. ${ }^{24}$ Recently, carbon nanodots (C-dots) prepared by various methods have shown promise as reducing agents towards the formation of $\mathrm{Au}$ and $\mathrm{Ag}$ NPs, ${ }^{25-35}$ owing to their intrinsic abilities to act as electron donors and/or acceptors. ${ }^{36}$ For instance, Luo and coworkers demonstrated that electrochemically-synthesized Cdots functioned as reducing and stabilizing agents in the preparation of Au@C-dot nanocomposites that displayed tuneable particle diameters by varying the chloroauric acid : Cdot ratio. ${ }^{35}$ Similarly, Shen et al. reported the reductive capabilities of hydrothermally synthesized C-dots for AgNP growth 
with the resultant AgNP size varying when the silver nitrate : Cdot ratio was altered..$^{34}$

Since the serendipitous discovery of C-dots over a decade ago, research into their formation and application has grown exponentially due to their many attractive optical and physical properties, including large red-edge effects (excitation wavelength-dependant emission), electron donor/acceptor capabilities, high aqueous solubility, large photostability, and low cytotoxity. ${ }^{37-48}$ Despite the "green" nature of C-dots, in general, many synthetic approaches often involve unsustainable precursors, harsh acidic/alkaline conditions, high synthetic temperatures, or extensive pre-/post-treatments which are inconsistent with the principles of green chemistry, for example routes involving arc-discharge, ${ }^{38}$ laser ablation, ${ }^{39}$ and acid oxidations. ${ }^{40,41}$ Therefore, greener synthetic strategies such as microwave, thermal, or hydrothermal treatment of various sustainable precursors (citric acid, ${ }^{42,43}$ urea $^{43}$ ) or even low-value waste materials (e.g., grass,$^{44}$ fruit peels, such as pomelo ${ }^{45}$ watermelon, ${ }^{46}$ banana, ${ }^{47}$ orange ${ }^{48}$ ) are being aggressively pursued. Recently, Dong et al. showed that, via a simple thermal degradation of solid citric acid, one could selectively generate either C-dots or graphene oxide, depending upon the degree of carbonization. $^{42}$

In this communication, we report on the thermal degradation of solid citric acid to produce C-dots following methods slightly modified from that reported by Dong and co-workers. The resultant C-dots were competent reducing agents for the thermally-assisted formation of AgNPs as well as the ambienttemperature synthesis of AuNPs. Similar to previous reports, ${ }^{34,35}$ varying the C-dot : metal salt ratio resulted in different MNP sizes and morphologies, an influence reflected in the observed SPRs. Interestingly, the C-dots were also effective for the coreduction of both $\mathrm{Au}$ and $\mathrm{Ag}$ salts to synthesize $\mathrm{Au}_{x} \mathrm{Ag}_{y} @ \mathrm{C}-\mathrm{dot}$ BMNPs. To the best of our knowledge, this is the first example of BMNP formation using C-dots as the reducing and stabilizing agent. Due to the synergistic effect of the two metals, the $\mathrm{Au}_{x^{-}}$ $\mathrm{Ag}_{y} @ \mathrm{C}$-dot BMNPs showed marked improvements in the catalytic reduction of 4-nitrophenol (4-NP) over its monometallic $\mathrm{Au} @ C-d o t$ NPs counterpart. Perhaps more surprisingly, the Ag@C-dot NPs possessed catalytic activities similar to that of the $\mathrm{Au}_{0.5} \mathrm{Ag}_{0.5} @ \mathrm{C}-$ dot NPs.

The detailed experimental procedures and characterizations of the C-dots are provided in the (ESI $\dagger$ ). Briefly, $50 \mathrm{~g}$ of solid citric acid (CA) was thermally decomposed at $250{ }^{\circ} \mathrm{C}$ for $2 \mathrm{~h}$. The resultant dark red product was re-dispersed in deionized water, centrifuged, dialyzed, and then lyophilized. The CA-derived Cdots displayed properties akin to those of previously reported Cdots. ${ }^{37,46,48}$ The citrate-derived C-dots showed an increasing absorbance with decreasing wavelength (Fig. S1A, $\dagger$ dashed black line) which arises from the $\pi-\pi^{*}$ transition of aromatic $\mathrm{sp}^{2}$ domains and is likely due to the broad size distribution of Cdots produced. ${ }^{46,48}$ Similar to other reported C-dots, ${ }^{37,46}$ the CAderived C-dots displayed excitation wavelength-dependent emission with a maximum emission occurring near $470 \mathrm{~nm}$ under $350 \mathrm{~nm}$ excitation (Fig. S1A $\dagger$ ). The emission intensity increased as the excitation wavelength was increased from 300 to $350 \mathrm{~nm}$ after which it decreased and redshifted. The decrease in emission is further highlighted and quantified by the excitation wavelength-dependent quantum yields (Fig. S1A, $\dagger$ inset). The resultant CA-derived C-dots were slightly larger than those typically reported in the literature (1-10 nm), ${ }^{37}$ ranging in size from 30-60 nm with some dots reaching $100 \mathrm{~nm}$ (Fig. S1B $\dagger$ ).

Fourier-transform infrared (FTIR) spectroscopic analysis indicated that the C-dots possessed hydroxyl, carboxyl, and epoxide moieties, accounting for their hydrophilicity and excellent dispersibility in water (Fig. $\mathrm{S} 1 \mathrm{C} \dagger$ ). ${ }^{42}$ The large, broad absorption bands between $3600-3000 \mathrm{~cm}^{-1}$ were assigned to the stretching vibrations of $\mathrm{O}-\mathrm{H}\left(\nu_{\mathrm{O}-\mathrm{H}}\right)$. Well-defined absorbance bands appeared between $1800 \mathrm{~cm}^{-1}$ and $1600 \mathrm{~cm}^{-1}$ which were ascribed to the stretching vibrations of $\mathrm{C}=\mathrm{O}\left(\nu_{\mathrm{C}}=\mathrm{O}\right)$ and the skeletal vibrations of aromatic groups $\left(\nu_{\mathrm{C}=\mathrm{C}}\right)$. The various peaks between $1300-1000 \mathrm{~cm}^{-1}$ arose from the different stretching modes of carboxylic, ester, ether, and alcohol moieties $\left(\nu_{\mathrm{C}-\mathrm{O}-\mathrm{C}}\right.$ and $\left.\nu_{\mathrm{C}-\mathrm{OH}}\right)$, while the peaks near 2900, 1400, and 915 $\mathrm{cm}^{-1}$ were attributed to aliphatic carbons $\left(\nu_{\mathrm{C}-\mathrm{H}}\right.$ and $\left.\nu_{=\mathrm{C}-\mathrm{H}}\right)$. The presence of these functionalities account for the long-term dispersibility of C-dots in water. Due to these surface functionalities and based on previous literature reports, ${ }^{25-35}$ we posited that the CA-derived C-dots would likely function as reducing as well as capping agents in the formation of MNPs. After optimizing the reaction conditions (refer to the ESI $\dagger$ for specific details), we found that C-dots were capable of directly reducing $\mathrm{HAuCl}_{4}$ to AuNPs at room temperature whereas $\mathrm{Ag}$ reduction required alkaline conditions and elevated temperatures with the most promising results achieved using $20 \mathrm{mM}$ $\mathrm{NaOH}(\mathrm{pH}>10)$ and a reaction temperature of $100{ }^{\circ} \mathrm{C}$.

For the room temperature reduction of $\mathrm{HAuCl}_{4}$, various ratios of C-dots : $\mathrm{HAuCl}_{4}$ were tested in two fashions: (1) using a constant C-dot concentration for varying Au precursor additions and (2) maintaining a constant $\mathrm{HAuCl}_{4}$ concentration for varying C-dot additions. A given concentration of $\mathrm{HAuCl}_{4}(0.3$ $\mathrm{mM})$ with increasing amounts of C-dots $\left(0.05-0.60 \mathrm{mg} \mathrm{mL}^{-1}\right)$ resulted in increased SPR intensities accompanied by a blueshift (indicative of smaller AuNPs) until the C-dot concentration reached $0.30 \mathrm{mg} \mathrm{mL}{ }^{-1}$, after which the SPR intensities remained relatively constant and presented a negligible shift in wavelength (Fig. S2 $\dagger$ ). On the other hand, for a given concentration of C-dots $\left(0.30 \mathrm{mg} \mathrm{mL}^{-1}\right)$ plus increasing amounts of $\mathrm{HAuCl}_{4}(0.10-0.60 \mathrm{mM} ; 0.05 \mathrm{mM}$ increments $)$, the SPR increased and drastically red-shifted (indicative of larger AuNPs) pointing towards the potential tunability of the resultant AuNPs (Fig. 1B and C). Specifically, between Au concentrations of 0.10 to $0.35 \mathrm{mM}$, a slight bathochromic shift arose accompanied by an increase in SPR intensities while for $\mathrm{Au}$ concentrations greater than $0.35 \mathrm{mM}$, a large bathochromic shift in the SPR was apparent. At these higher concentrations of $\mathrm{Au}$, the SPR intensities increased up to $0.45 \mathrm{mM}$, after which the SPRs decreased and substantial peak broadening occurred (indicative of larger, more polydisperse AuNPs). Based on these results, the C-dots appeared to function effectively as both reducing and stabilizing agents. The results also indicate the clear potential for fine-tuning the Au SPR (Fig. 1C), and concurrently the AuNP size, simply by varying the C-dot: Au ratio. 

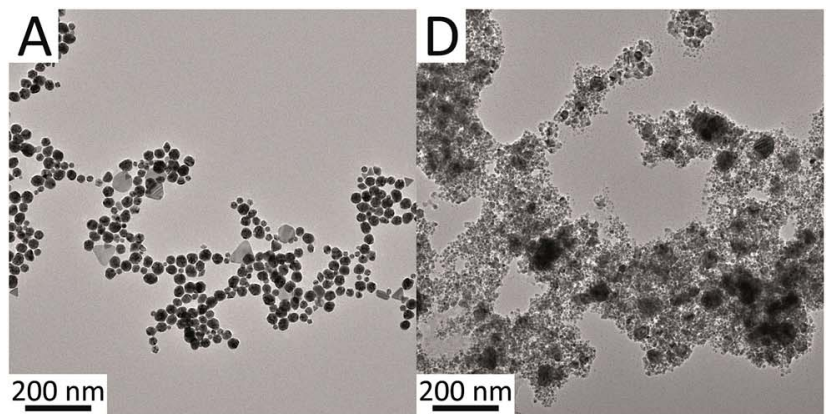

$2 \underline{00 \mathrm{~nm}}$
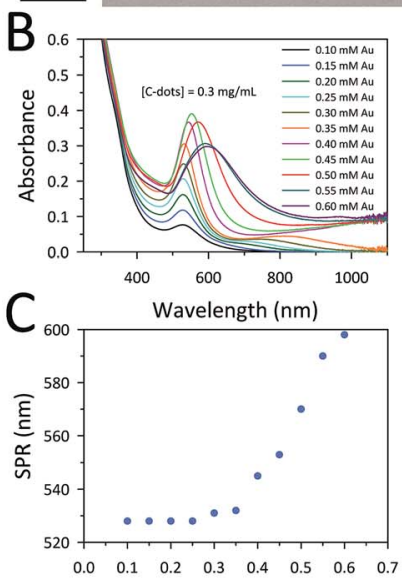

Au Concentration (mM)
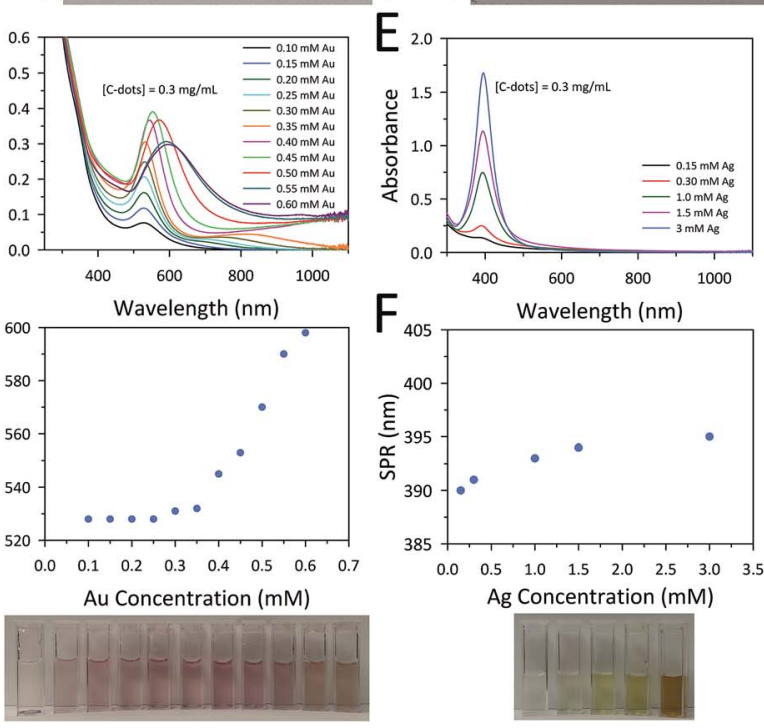

Ag Concentration (mM)

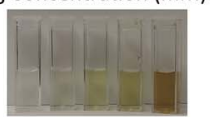

Fig. 1 Representative TEM images of (A) Au@C-dot and (D) Ag@C-dot NPs. Shown are results for $0.3 \mathrm{mg} \mathrm{mL}^{-1}: 0.35 \mathrm{mM}$ and $0.3 \mathrm{mg}$ $\mathrm{mL}^{-1}: 0.30 \mathrm{mM} \mathrm{C}$-dots : metal ratios for $\mathrm{Au}$ and $\mathrm{Ag}$ reductions, respectively. The SPR shifts of the resultant particles $(B-F)$ show the smooth tunability afforded simply by changing the $C$-dot : metal ratio. In the case of AuNPs (B and C), the SPR intensity initially increased, reaching a maximum at a $0.3 \mathrm{mg} \mathrm{mL}^{-1} \mathrm{C}$-dot : $0.45 \mathrm{mM}$ Au ratio. The increase was also accompanied by a slight bathochromic shift. Higher $\mathrm{Au}$ : C-dot ratios resulted in a continuous red-shift with decreasing SPR intensity and substantial peak broadening, indicative of larger, more polydisperse NPs. On the other hand, the AgNPs displayed only a slight bathochromic shift ( $E$ and F) in SPR, with increasing intensities as the $\mathrm{Ag}$ concentration was varied from 0.15 to $3 \mathrm{mM}$. The lower images correspond to the $\mathrm{Au}$ and $\mathrm{Ag}$ samples in (B and $\mathrm{C}$ ) and ( $\mathrm{E}$ and $\mathrm{F}$ ), respectively.

The SPR bathochromic shift and peak broadening were attributed to an increase in particle size and a greater polydispersity, respectively, as evidenced in Fig. S3.† For example, the $0.20 \mathrm{mM}, 0.35 \mathrm{mM}, 0.45 \mathrm{mM}$, and $0.60 \mathrm{mM}$ Au concentrations resulted in $17.8 \pm 6.4,26.7 \pm 10.0,47.8 \pm 20.7$, and $96.7 \pm$ $29.9 \mathrm{~nm}$ quasi-spherical particles, respectively. The $0.3 \mathrm{mg}$ $\mathrm{mL}^{-1}: 0.35 \mathrm{mM}$ C-dot: Au ratio is also shown in Fig. 1A. Moreover, for higher concentrations of $\mathrm{Au}$, large hexagonal and trigonal plates formed, with a higher amount of plate formation occurring with increasing Au : C-dot ratios. Although sample stability initially appeared to decrease for higher Au concentrations, the samples could be redispersed easily and the sedimentation was actually linked to the presence of large $\mathrm{Au}$ nanoplates which settled from solution within a couple days.
Indeed, the $0.45 \mathrm{mM}$ and $0.60 \mathrm{mM} \mathrm{Au}$ concentrations afforded $266.7 \pm 99.3$ and $528.8 \pm 214.3 \mathrm{~nm}$ plates with approximate quasi-spherical : plate ratios of $1: 5$ and $1: 2$, respectively. The increasing formation of large hexagonal and trigonal plates translated to substantial peak broadening within the UV-Vis spectra and a bathochromic shift of the SPR, resulting in a color transition of the solutions from red to blue/purple. Interestingly, the higher Au concentrations still produced a population of small AuNPs in the 5-20 nm size range (Fig. S3C and $\mathrm{D}^{\dagger}$ insets), however, these particles were relatively rare in these samples.

To gain additional insight into the reduction process and the photophysical characteristics of the Au@C-dots, the room temperature reduction of $0.3 \mathrm{mg} \mathrm{mL} \mathrm{mL}^{-1} \mathrm{C}$-dots : $0.35 \mathrm{mM}$ $\mathrm{HAuCl}_{4}$ samples was monitored via UV-Vis and fluorescence spectroscopy (Fig. S4†). After $180 \mathrm{~min}$, the intensity of the SPR band (absorbance at $544 \mathrm{~nm}$ ) was still increasing, although the SPR growth rate had begun to slow, indicating that the Au reduction was nearing completion (Fig. S4A $\dagger$ inset; left vertical axis). Throughout the reduction, the SPR remained consistently near $544 \mathrm{~nm}$ (Fig. S4A $\dagger$ inset; right vertical axis), elucidating that the increase in absorbance was due to the growth of additional NPs of a similar size rather than new species possessing different optical characteristics. Intriguingly, despite the intrinsic quenching nature of $\mathrm{Au}$, the Au@C-dots retained $\sim 25 \%$ of the original fluorescence from the C-dot parent (Fig. S4B $\dagger$ ). The inset plot of Fig. S4B $\dagger$ shows that, initially, the fluorescence rapidly decreased but eventually stabilized. Over the monitoring period, the wavelength of maximum emission from the C-dots remained relatively constant near $460 \mathrm{~nm}$.

Similar to the case for Au reduction, various C-dot : Ag ratios were tested at room temperature for potential reduction to AgNPs. In this case, no AgNP formation was evident even after a week's time. Based on its past use in promoting noble metal reduction, ${ }^{25,34}$ various concentrations of $\mathrm{NaOH}(1,10$, and 20 $\mathrm{mM}$ ) were added and elevated temperatures were employed (30, $50,70,90$, and $100{ }^{\circ} \mathrm{C}$ ) in an attempt to drive $\mathrm{Ag}^{+}$reduction. Although some AgNP formation was evident at lower temperatures and modest $\mathrm{NaOH}$ concentrations, the best results (on the basis of narrow and intense SPR bands) were achieved at $100^{\circ} \mathrm{C}$ using $20 \mathrm{mM} \mathrm{NaOH}$. Under these conditions, various C-dot : $\mathrm{Ag}$ ratios were assayed. The $\mathrm{Ag}$ reductions displayed a decreased SPR dependency on C-dot : metal ratios compared to their Au reduction counterparts. When the C-dot concentration was held constant $\left(0.3 \mathrm{mg} \mathrm{mL}{ }^{-1}\right)$ and increasing amounts of $\mathrm{Ag}^{+}$were added $(0.15-3.0 \mathrm{mM})$, the SPR intensity drastically increased (indicative of increased AgNP formation) whilst showing negligible shift in wavelength (Fig. 1E and F). On the other hand, when the $\mathrm{AgNO}_{3}$ concentration was held constant at $1.0 \mathrm{mM}$, for increasing amounts of C-dots from $0.05-0.60 \mathrm{mg} \mathrm{mL}^{-1}$, the SPR intensity again increased but displayed a small hypsochromic shift followed by a slight bathochromic shift (Fig. S5†). In spite of this slight SPR shift, an increasing Ag : C-dot ratio apparently generates slightly smaller AgNPs (Fig. S6†). A size analysis, conducted by counting over 200 particles per sample, resulted in mean particle sizes of $11.1 \pm 9.9,6.9 \pm 3.4$, and $6.0 \pm 4.0 \mathrm{~nm}$ for the $0.30 \mathrm{mM}, 1.0 \mathrm{mM}$, and $3.0 \mathrm{mM} \mathrm{Ag}$ concentrations, 
respectively. A representative TEM image for the Ag@C-dot sample derived from a $0.3 \mathrm{mg} \mathrm{mL}{ }^{-1}: 0.30 \mathrm{mM}$ C-dot: $\mathrm{Ag}$ sample is also shown in Fig. 1D.

Both the Ag@C-dot and Au@C-dot NPs, due to their plasmonic nature, hold prospects for SERS and photovoltaic applications, but to further enhance the applicability of these MNPs@C-dots, we attempted to simultaneously reduce both Ag and $\mathrm{Au}$ salts to generate $\mathrm{Au}_{x} \mathrm{Ag}_{y} @ \mathrm{C}-\mathrm{dot}$ BMNPs. The fact that we were only able to achieve Ag reduction to generate $\mathrm{Ag} @ \mathrm{C}$-dots under basic conditions required we tailor our synthetic approach in order to arrive at BMNPs. Firstly, $\mathrm{NaOH}$ was added to $\mathrm{HAuCl}_{4}$ to produce gold hydroxide, $\mathrm{Au}(\mathrm{OH})_{4}{ }^{-}$. The C-dot solution was then heated at $100{ }^{\circ} \mathrm{C}$ for $15 \mathrm{~min}$ to allow for thermal equilibration. Lastly, $\mathrm{Au}(\mathrm{OH})_{4}{ }^{-}$and $\mathrm{AgNO}_{3}$ solutions were simultaneously injected into the hot C-dot solution and allowed to react for $15 \mathrm{~min}$. In all instances, the C-dot, $\mathrm{NaOH}$, and total metal salt concentrations were held constant at $0.3 \mathrm{mg}$ $\mathrm{mL}^{-1}, 20 \mathrm{mM}$, and $1 \mathrm{mM}$, respectively. Aliquots of $10 \mathrm{mM}$ $\mathrm{HAuCl}_{4}$ and $10 \mathrm{mM} \mathrm{AgNO}_{3}$ were mixed to generate $\mathrm{Au}: \mathrm{Ag}$ ratios of $90: 10,80: 20,70: 30,60: 40,50: 50,40: 60,30: 70$, $20: 80$, and $10: 90$ (Fig. 2A). For example, to generate the $50: 50$ $\mathrm{Au}$ : Ag BMNP sample, $0.5 \mathrm{~mL}$ of $10 \mathrm{mM} \mathrm{HAuCl}_{4}$ was added to 2 $\mathrm{mL}$ of $100 \mathrm{mM} \mathrm{NaOH}$ which was simultaneously injected, alongside $0.5 \mathrm{~mL}$ of $10 \mathrm{mM} \mathrm{AgNO}$, into $7 \mathrm{~mL}$ of hot C-dot solution $\left(0.43 \mathrm{mg} \mathrm{mL}^{-1}\right)$. Samples containing $100 \% \mathrm{Ag}$ were made in analogous fashion, whereas the preparation of $100 \%$ $\mathrm{Au}$ samples involved no addition of $\mathrm{NaOH}$, in accordance with the Au@C-dot preparation method described earlier. It is noteworthy that the use of $\mathrm{Au}(\mathrm{OH})_{4}{ }^{-}$in the absence of $\mathrm{Ag}^{+}$at 100 ${ }^{\circ} \mathrm{C}$ led solely to the formation of large gold plates. As the $\mathrm{Au}: \mathrm{Ag}$ ratio decreased, the SPR uniformly blue-shifted, consistent with the presence of BMNPs (Fig. 2A and B)., ${ }^{9,24}$

Reminiscent of the room temperature reduction of $0.6 \mathrm{mM}$ $\mathrm{Au}$, use of $1 \mathrm{mM} \mathrm{HAuCl}$ at $100{ }^{\circ} \mathrm{C}$ yielded highly unstable particles which displayed a broad, red-shifted SPR. For this reason, the $100 \% \mathrm{Au}$ results reported in Fig. 2 were actually generated from $0.25 \mathrm{mM} \mathrm{HAuCl}_{4}$. The effect of Au concentration on the SPR was subsequently investigated for reduction at 100 ${ }^{\circ} \mathrm{C}$. These results again reiterate the strong control over the SPR made possible simply by varying the ratio of $\mathrm{Au}$ : C-dots (Fig. S7 $\dagger$ ). To verify that the C-dots were indeed responsible for the reduction of the BMNPs, a control reaction was performed for a $50: 50 \mathrm{Au}: \mathrm{Ag}$ sample in the absence of C-dots (Fig. S8†). The lack of both a SPR band and a visible change in solution color indicated that the C-dots were solely responsible for accomplishing metal ion reduction.

Both the Au@C-dot and Ag@C-dot NPs displayed larger particle sizes than all of their bimetallic counterparts (Fig. 3A-C and $\mathrm{S} 9 \dagger)$. Interestingly, upon the addition of $10 \% \mathrm{Ag}$, the average particle size dramatically decreased from $30.0 \pm 6.0 \mathrm{~nm}$ for the Au@C-dot NPs to $4.1 \pm 1.4 \mathrm{~nm}$ for the $\mathrm{Au}_{0.9} \mathrm{Ag}_{0.1} @ \mathrm{C}-\mathrm{dot}$ NPs. Increasing the $\mathrm{Ag}: \mathrm{Au}$ ratio within the BMNPs led to further decreased particle size. For the $\mathrm{Au}_{0.7} \mathrm{Ag}_{0.3} @ \mathrm{C}$-dot, $\mathrm{Au}_{0.5} \mathrm{Ag}_{0.5} @ \mathrm{C}-\mathrm{dot}, \mathrm{Au}_{0.3} \mathrm{Ag}_{0.7} @ \mathrm{C}-\mathrm{dot}$, and $\mathrm{Au}_{0.1} \mathrm{Ag}_{0.9} @ \mathrm{C}-\mathrm{dot}$ BMNPs, the average particle sizes were $3.4 \pm 0.9,3.3 \pm 1.1,2.4 \pm$ 0.8 , and $1.9 \pm 0.7 \mathrm{~nm}$, respectively. Although a small decrease in particle size was present, the dependence of the SPR maximum
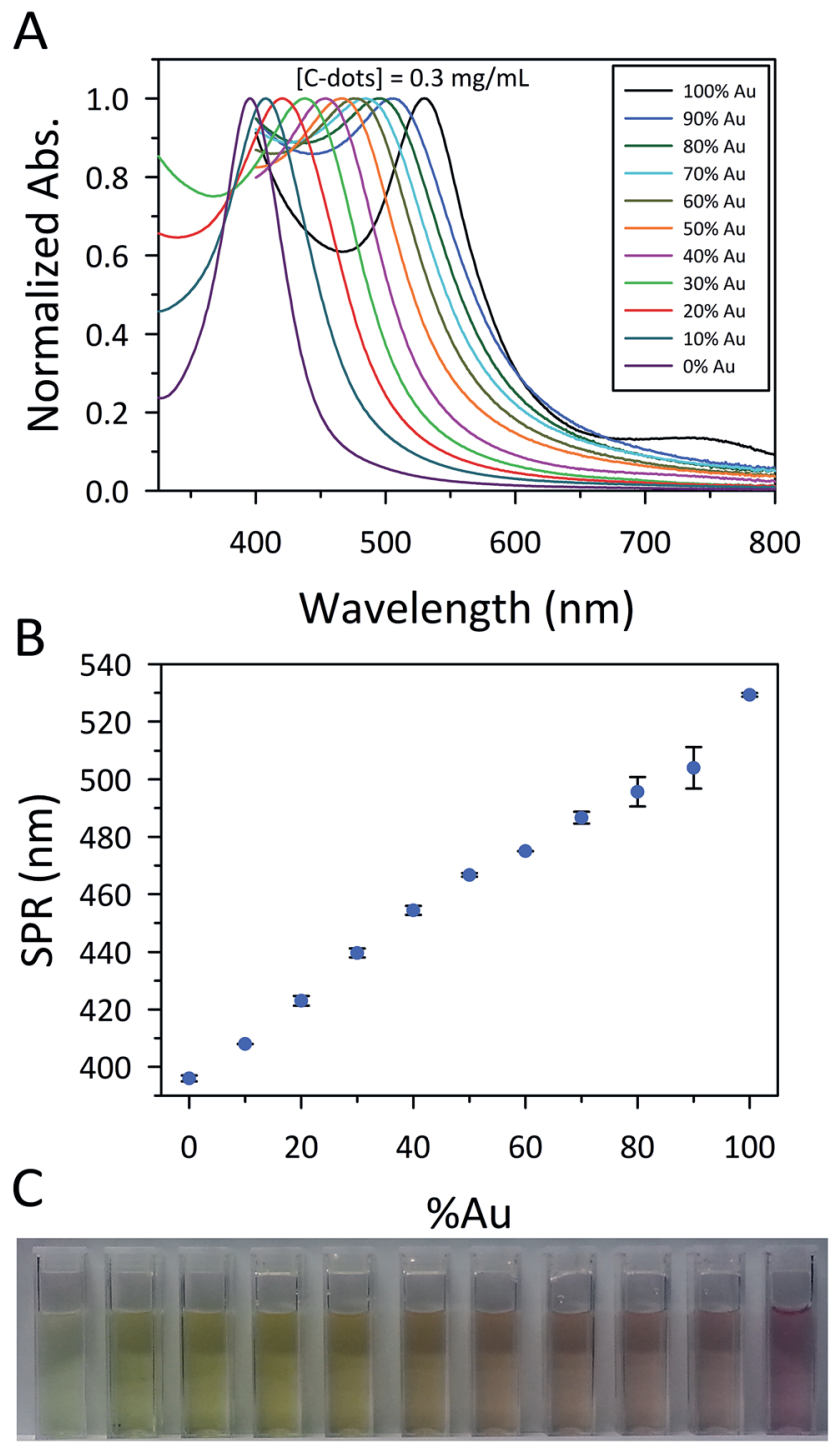

Fig. 2 (A) Normalized UV-Vis absorbance of the bimetallic $\mathrm{Au}_{x} \mathrm{Ag}_{y} @ \mathrm{C}$ dot NPs showing that as the experimental Au : Ag ratio decreased the resultant SPR displayed a systematic hypsochromic shift. (B) Extracted SPR frequencies plotted versus the \%Au, further demonstrating the smooth evolution in SPR wavelength as the Au : Ag ratio was modulated. The sample sets were replicated three times highlighting the reproducibility of the BMNPs (error bars denote one standard deviation from the mean), especially at the lower $A u$ concentrations. (C) Photograph of a series of $\mathrm{Au}_{x} \mathrm{Ag}_{y}(\mathrm{aC}$-dot BMNP samples, illustrating a palette of SPR transitions. The cuvettes correspond to the samples in A and $\mathrm{B}$ from (left) $100 \% \mathrm{Ag}$ to (right) $100 \% \mathrm{Au}$.

on the $\mathrm{Au}: \mathrm{Ag}$ ratio was primarily related to different levels of alloying and therefore synergistic plasmonic cooperation between the two metals.

Energy-dispersive X-ray (EDX) microanalysis of $\mathrm{Au}_{x} \mathrm{Ag}_{y} @ \mathrm{C}$ dot NPs was performed to reveal the average composition of the BMNPs (Fig. 3D-F). As expected, as the $\mathrm{Au}: \mathrm{Ag}$ ratio decreased, the $\mathrm{Au}$ peaks became less prominent whereas the $\mathrm{Ag}$ peaks became dominant. Fig. 3G shows that the actual composition of the $\mathrm{Au}_{x} \mathrm{Ag}_{y}$ @C-dot NPs was nominally the same as the starting $\mathrm{Au}: \mathrm{Ag}$ ratios, although for $\mathrm{Au}: \mathrm{Ag}$ fractions 

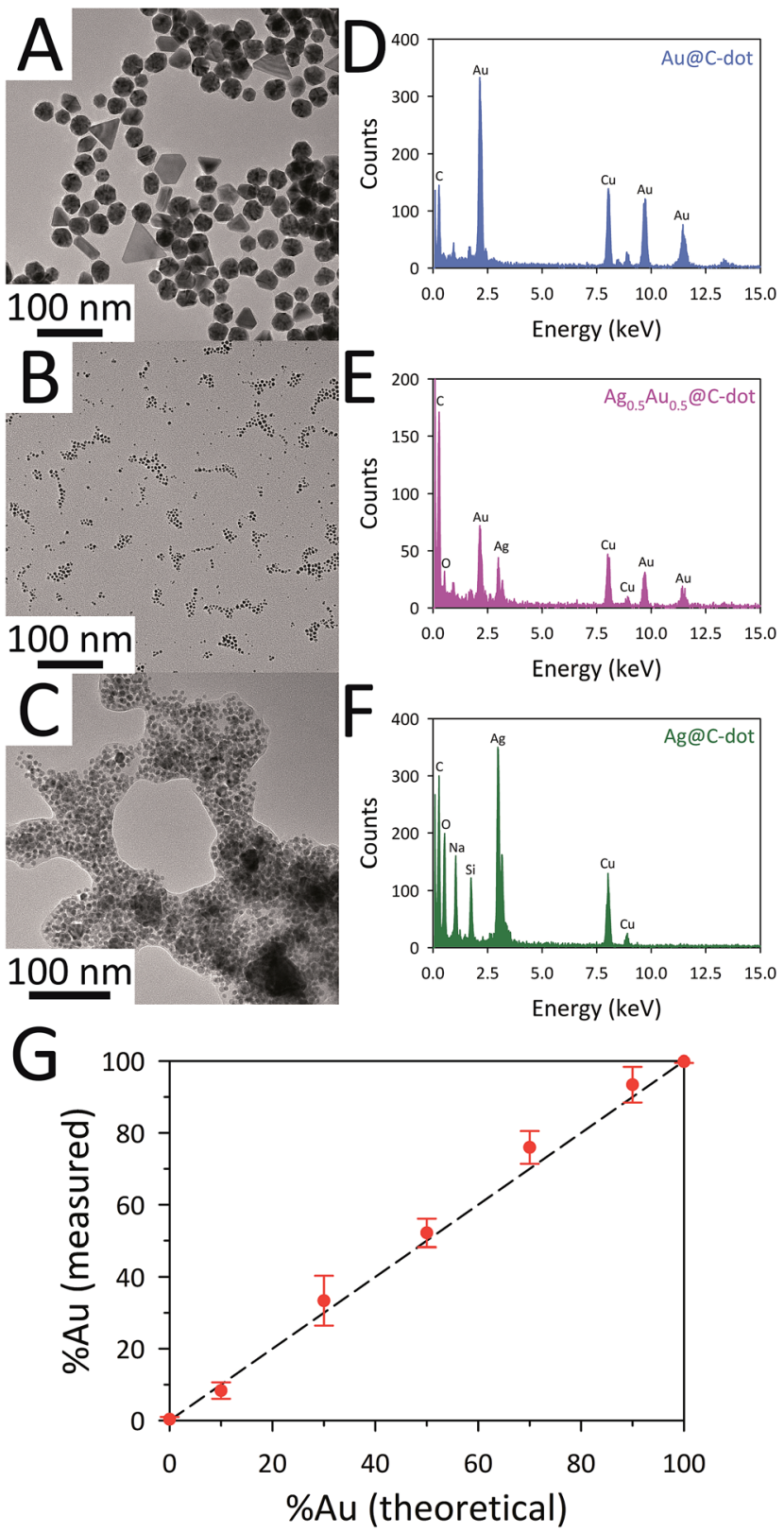

Fig. 3 Representative TEM images and their corresponding EDX spectra for (A and D) Au(CC-dots, (B and E) bimetallic Au ${ }_{0.5} \mathrm{Ag}_{0.5} \mathrm{QC}$ dots, and ( $C$ and F) Ag@C-dots. Interestingly, upon the slightest addition of silver, the NP's average size decreased by a factor of $\sim 7$ and remained relatively constant across the $\mathrm{Au}$ : Ag composition tested. (G) Plot showing the extent of alloying between $\mathrm{Au}$ and $\mathrm{Ag}$ (\%Au measured) within the BMNPs versus the content predicted from the initial Au: Ag stoichiometry (i.e., \%Au theoretical). The dashed line represents the ideal case where the measured values directly correspond to reagent metallic ratios. In general, the measured content follows the prediction line. The slight enrichment with Au at higher initial Au\% could be tentatively tied to a small amount of galvanic replacement in which $\mathrm{Ag}^{0}$ is etched by $\mathrm{Au}^{3+}$

greater than $20: 80$, a slight enrichment in Au arose, possibly due to some galvanic replacement of $\mathrm{Ag}$ with $\mathrm{Au}$. The $\mathrm{Cu}$ peaks present in the EDX spectra simply arose from the grids employed for imaging.
The catalytic activities of the MNPs@C-dots were studied through the model reduction of 4-nitrophenol (4-NP) to 4-aminophenol (4-AP) using $\mathrm{NaBH}_{4}$ as the reducing agent. The reaction kinetics of the catalytic conversion were monitored by UVVis spectroscopy. The aqueous solution of 4-NP displays little (pale yellow) to no color with an absorbance band at $320 \mathrm{~nm}$. Upon the addition of $\mathrm{NaBH}_{4}$, the solution immediately turns dark yellow due to the formation of the 4-nitrophenolate ion (4NPO). The formation of 4-NPO results in an increased absorbance accompanied by a bathochromic shift to $400 \mathrm{~nm}$. To test for catalytic activities, UV-Vis spectra were collected every $5 \mathrm{~s}$ following injection of $\mathrm{NaBH}_{4}$, monitoring the decreased absorption at $400 \mathrm{~nm}$ (i.e., loss of 4-NP). The 4-NP to 4-AP conversion was unaltered in the presence of the CA-derived Cdots $\left(5.8 \mu \mathrm{g} \mathrm{mL} \mathrm{m}^{-1}\right)$ even after $30 \mathrm{~min}$, demonstrating that unmodified C-dots are not catalysts for this reaction (Fig. 4B; only shown out to $450 \mathrm{~s}$ ). Upon addition of MNPs@C-dots to the 4-NPO solution, however, a prompt drop in absorbance at 400 $\mathrm{nm}$ was observed within seconds, indicating the rapid conversion of 4-NP to 4-AP (Fig. 4A; S10, $\dagger$ panels A and B). The complete reduction of 4-NP to 4-AP was observed within $120 \mathrm{~s}$, $150 \mathrm{~s}$, and $>1000 \mathrm{~s}$ for $\mathrm{Ag} @ \mathrm{C}$-dots, $\mathrm{Au}_{0.5} \mathrm{Ag}_{0.5} @ \mathrm{C}$-dots, and Au@C-dots, respectively. The reduction mechanism can be explained through the Langmuir-Hinshelwood mechanism, in which the analyte of interest (4-NPO) absorbs on the surface of the MNPs, while the MNPs also react with the $\mathrm{BH}_{4}{ }^{-}$to form a metal hydride. The metal hydride then reacts with the sorbed analyte (4-NPO), facilitating its reduction. Due to the slow transfer of electrons from the metal hydride to 4 -NPO, it is considered the rate determining step of the reaction. ${ }^{49}$ This lag phase or induction time $\left(t_{\mathrm{o}}\right)$ in the reaction rate was minimized by degassing the 4-NP solution for 20 min to remove any dissolved oxygen. Despite this preventative measure, lag phases were still observed in the Au@C-dot NP samples. In this study, an excess amount (1000-fold) of $\mathrm{NaBH}_{4}(0.2 \mathrm{M}, 0.4 \mathrm{~mL})$ compared to $4-\mathrm{NP}$ was used $(0.2 \mathrm{mM}, 0.4 \mathrm{~mL})$ so that the conversion would follow a pseudo-first-order rate law. Under these conditions, the apparent rate constants $\left(k_{\text {app }}\right)$ for each catalyst can be estimated from the slopes of the linear correlation of $\ln \left(A_{t} / A_{\mathrm{o}}\right)$ versus time, where $A_{\mathrm{o}}$ is the initial absorbance and $A_{t}$ is the absorbance at time $(t)$. The $k_{\text {app }}$ values for Ag@Cdot, $\mathrm{Au}_{0.5} \mathrm{Ag}_{0.5} @ \mathrm{C}$-dot, and $\mathrm{Au} @ \mathrm{C}$-dot catalysts were $2.30 \pm 0.25$ $\times 10^{-2} \mathrm{~s}^{-1}, 1.92 \pm 0.43 \times 10^{-2} \mathrm{~s}^{-1}$, and $2.54 \pm 0.30 \times 10^{-3} \mathrm{~s}^{-1}$, respectively (Fig. 4B). Thus, the $\mathrm{Au}_{0.5} \mathrm{Ag}_{0.5} @ \mathrm{C}-\mathrm{dot}$ and $\mathrm{Ag} @ \mathrm{C}-\mathrm{dot}$ catalysts showed improved activities (faster 4-NP reduction) over the Au@C-dot NPs, an outcome attributed to their smaller sizes and therefore higher surface areas.

All three types of MNPs@C-dots retained their catalytic activities after months of storage in a lab drawer. Even after 5 months of casual, ambient storage, the apparent rate constants for 4-NP reduction were completely preserved. In fact, surprisingly, the $\mathrm{Ag} @ \mathrm{C}-\mathrm{dot}$ and $\mathrm{Au}_{0.5} \mathrm{Ag}_{0.5} @ \mathrm{C}-\mathrm{dot} \mathrm{NPs}$ displayed statistically meaningful increases in their catalytic rates. The $k_{\text {app }}$ for the 5 month aged $\mathrm{Ag} @ \mathrm{C}-\mathrm{dot}, \mathrm{Au}_{0.5} \mathrm{Ag}_{0.5} @ \mathrm{C}-\mathrm{dot}$, and Au@C-dot catalysts were $3.83 \pm 0.30 \times 10^{-2} \mathrm{~s}^{-1}, 2.69 \pm 0.39 \times$ $10^{-2} \mathrm{~s}^{-1}$, and $2.98 \pm 0.22 \times 10^{-3} \mathrm{~s}^{-1}$, respectively (Fig. S10C $\dagger$ ). Since the aged $\mathrm{Ag} @ \mathrm{C}$-dot and $\mathrm{Au}_{0.5} \mathrm{Ag}_{0.5} @ \mathrm{C}$-dot NPs showed 

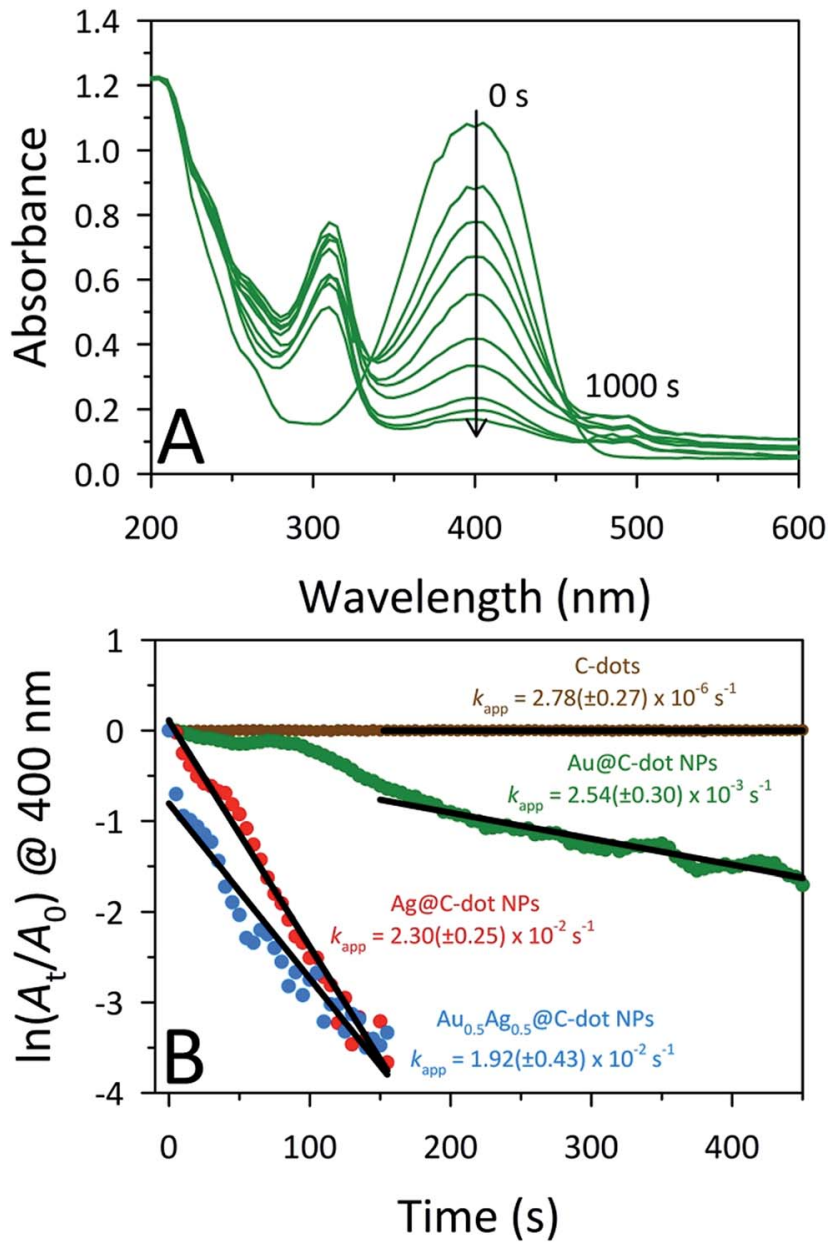

Fig. 4 (A) Time-dependent UV-Vis absorption spectra of the $\mathrm{NaBH}_{4}$ assisted reduction of 4-NP catalyzed by the AuaC-dot NPs. Spectra were acquired every $5 \mathrm{~s}$ but, for clarity, spectra are shown only for illustrative times. (B) Plots of $\ln \left(A_{t} / A_{\circ}\right)$ for $4-N P$ absorbance at $400 \mathrm{~nm}$ against time for various MNPaC-dot catalysts. Each catalyst was tested within days of preparation.

improved catalytic rates over the corresponding freshly prepared NPs, UV-Vis studies were conducted on both the aged and freshly prepared NPs to monitor any optical changes (Fig. S11 $\dagger$ ). The Au@C-dot NPs essentially remained unchanged after 5 months while the aged $\mathrm{Au}_{0.5} \mathrm{Ag}_{0.5} @ \mathrm{C}-\mathrm{dot}$ and $\mathrm{Ag} @ \mathrm{C}-\mathrm{dot}$ NPs displayed increased absorbance at longer wavelengths, possibly due to minor nanoparticle aggregation. The slight particle aggregation upon prolonged storage may have resulted in catalytic hotspots, accounting for the marginal increase in catalytic activity of the aged $\mathrm{Ag} @ \mathrm{C}-d o t$ and $\mathrm{Au}_{0.5} \mathrm{Ag}_{0.5} @ \mathrm{C}$-dot NPs. Due to the surprisingly high catalytic rate of the Ag@C-dot NPs and gold's established reputation as a good catalyst for this reaction, the improved catalytic rates of the BMNPs could be attributed to a synergistic effect of $\mathrm{Au}$ and $\mathrm{Ag}$ nano-domains within the individual particles, in line with results reported recently by Ravula et al. ${ }^{9}$

Lastly, we examined the potential of the MNP@C-dot samples as peroxidase mimetics toward oxidation of the peroxidase substrate 2,2'-azino-bis(3-ethylbenzothiazoline-6- sulphonic acid) diammonium salt (ABTS) using $\mathrm{H}_{2} \mathrm{O}_{2}$. While neither $\mathrm{Au}_{0.5} \mathrm{Ag}_{0.5} @ \mathrm{C}$-dots nor $\mathrm{Ag} @ \mathrm{C}$-dots displayed any measureable peroxidase activity within $24 \mathrm{~h}$ of prospective catalyst addition, the Au@C-dots demonstrated clear activity. As summarized in Fig. S12, $\dagger$ addition of Au@C-dots triggered the formation of green-colored ABTS oxidation product which was monitored spectrophotometrically at $418 \mathrm{~nm}$. A control experiment carried out using citric acid-derived C-dots alone did not yield noticeable peroxidase activity. A dramatic increase in the catalytic velocity was observed in the time-dependent absorption profiles as the Au@C-dot content was increased, validating the intrinsic peroxidase activity of the Au@C-dots in contrast with the naked C-dots. Among other things, these data open the possibility of using hybrid C-dots for selective glucose detection by coupling with glucose oxidase, for example.

In summary, we have demonstrated a simple and green approach towards the synthesis of MNPs/BMNPs using C-dots as the reducing and stabilizing agent. The resultant SPR of the various MNPs and BMNPs showed a systematic tunability indicating that the size of NPs can easily be controlled simply by varying the $\mathrm{C}$-dot: metal ratio. The $\mathrm{Au}_{x} \mathrm{Ag}_{y}$ @C-dot metal compositions were nominally the same as the starting stoichiometric ratios, pointing to the efficiency of this nanoscale preparation. Notably, the Ag@C-dot NPs and $\mathrm{Au}_{x} \mathrm{Ag}_{y} @ \mathrm{C}-\mathrm{dot}$ BMNPs displayed remarkably enhanced catalytic activities over Au@C-dots for 4-nitrophenol reduction, highlighting the potential of these materials in various catalytic applications. Finally, the Au@C-dots showed peroxidase activity not seen in the unmodified C-dots nor in their Ag@C-dot NPs and $\mathrm{Au}_{x^{-}}$ $\mathrm{Ag}_{y}$ @C-dot analogs. In the future, these materials might find use in additional areas such as surface-enhanced spectroscopies and plasmon-assisted photovoltaics.

\section{Acknowledgements}

We thank Drs Tommi White and Thomas Lam of the MU Electron Microscopy Core Facility for assistance with our nanoparticle imaging.

\section{References}

1 S. Saha, A. Pal, S. Kundu, S. Basu and T. Pal, Langmuir, 2009, 26, 2885-2893.

2 J. Qi, X. Dang, P. T. Hammond and A. M. Belcher, ACS Nano, 2011, 5, 7108-7116.

3 S. D. Standridge, G. C. Schatz and J. T. Hupp, J. Am. Chem. Soc., 2009, 131, 8407-8409.

4 V. K. Sharma, R. A. Yngard and Y. Lin, Adv. Colloid Interface Sci., 2009, 145, 83-96.

5 S. Chernousova and M. Epple, Angew. Chem., Int. Ed., 2013, 52, 1636-1653.

6 Z. Mu, X.-W. Zhao, Z. Xie, Y. Zhao, Q.-F. Zhong, L. Bo and Z.-Z. Gu, J. Mater. Chem. B, 2013, 1, 1607-1613.

7 H. Chang, H. Kang, J.-K. Yang, A. Jo, H.-Y. Lee, Y.-S. Lee and D. H. Jeong, ACS Appl. Mater. Interfaces, 2014, 6, 1185911863. 
8 K. K. Haldar, S. Kundu and A. Patra, ACS Appl. Mater. Interfaces, 2014, 6, 21946-21953.

9 S. Ravula, J. B. Essner, W. A. La, L. Polo-Parada, R. Kargupta, G. J. Hull, S. Sengupta and G. A. Baker, Nanoscale, 2015, 7, 86-91.

10 I. Lee, S. W. Han and K. Kim, Chem. Commun., 2001, 17821783.

11 L. M. Liz-Marzan and A. P. Philipse, J. Phys. Chem., 1995, 99, 15120-15128.

12 N. N. Kariuki, J. Luo, M. M. Maye, S. A. Hassan, T. Menard, H. R. Naslund, Y. Lin, C. Wang, M. H. Engelhard and C.-J. Zhong, Langmuir, 2004, 20, 11240-11246.

13 D.-H. Chen and C.-J. Chen, J. Mater. Chem., 2002, 12, 15571562.

14 O. V. Kharissova, H. V. R. Dias, B. I. Kharisov, B. O. Pérez and V. M. J. Pérez, Trends Biotechnol., 2013, 31, 240-248.

15 A. K. Mittal, Y. Chisti and U. C. Banerjee, Biotechnol. Adv., 2013, 31, 346-356.

16 A. Bankar, B. Joshi, A. R. Kumar and S. Zinjarde, Colloids Surf., A, 2010, 368, 58-63.

17 A. Bankar, B. Joshi, A. Ravi Kumar and S. Zinjarde, Colloids Surf., B, 2010, 80, 45-50.

18 M. N. Nadagouda, N. Iyanna, J. Lalley, C. Han, D. D. Dionysiou and R. S. Varma, ACS Sustainable Chem. Eng., 2014, 2, 1717-1723.

19 H. Xu, L. Wang, H. Su, L. Gu, T. Han, F. Meng and C. Liu, Food Biophys., 2014, 1-7.

20 A. Rao, K. Mahajan, A. Bankar, R. Srikanth, A. R. Kumar, S. Gosavi and S. Zinjarde, Mater. Res. Bull., 2013, 48, 11661173.

21 V. Ganesh Kumar, S. Dinesh Gokavarapu, A. Rajeswari, T. Stalin Dhas, V. Karthick, Z. Kapadia, T. Shrestha, I. A. Barathy, A. Roy and S. Sinha, Colloids Surf., B, 2011, 87, 159-163.

22 G. A. Kahrilas, L. M. Wally, S. J. Fredrick, M. Hiskey, A. L. Prieto and J. E. Owens, ACS Sustainable Chem. Eng., 2013, 2, 367-376.

23 M. N. Alam, S. Das, S. Batuta, N. Roy, A. Chatterjee, D. Mandal and N. A. Begum, ACS Sustainable Chem. Eng., 2014, 2, 652-664.

24 M. Meena Kumari, J. Jacob and D. Philip, Spectrochim. Acta, Part A, 2015, 137, 185-192.

25 L.-M. Shen, Q. Chen, Z.-Y. Sun, X.-W. Chen and J.-H. Wang, Anal. Chem., 2014, 86, 5002-5008.

26 X. Wang, Y. Long, Q. Wang, H. Zhang, X. Huang, R. Zhu, P. Teng, L. Liang and H. Zheng, Carbon, 2013, 64, 499-506.
27 S. Mandani, B. Sharma, D. Dey and T. K. Sarma, Nanoscale, 2015, 7, 1802-1808.

28 S. Liu, B. Yu and T. Zhang, RSC Adv., 2014, 4, 544-548.

29 H. Choi, S.-J. Ko, Y. Choi, P. Joo, T. Kim, B. R. Lee, J.-W. Jung, H. J. Choi, M. Cha, J.-R. Jeong, I.-W. Hwang, M. H. Song, B.-S. Kim and J. Y. Kim, Nat. Photonics, 2013, 7, 732-738.

30 Y. Choi, G. H. Ryu, S. H. Min, B. R. Lee, M. H. Song, Z. Lee and B.-S. Kim, ACS Nano, 2014, 8, 11377-11385.

31 R. Liu, J. Liu, W. Kong, H. Huang, X. Han, X. Zhang, Y. Liu and Z. Kang, Dalton Trans., 2014, 10920-10929.

32 X. Ran, H. Sun, F. Pu, J. Ren and X. Qu, Chem. Commun., 2013, 49, 1079-1081.

33 A. Jaiswal, P. Gautam, S. Ghosh and A. Chattopadhyay, J. Nanopart. Res., 2013, 16, 1-14.

34 L.-M. Shen, M.-L. Chen, L.-L. Hu, X.-W. Chen and J.-H. Wang, Langmuir, 2013, 29, 16135-16140.

35 P. Luo, C. Li and G. Shi, Phys. Chem. Chem. Phys., 2012, 14, 7360-7366.

36 X. Wang, L. Cao, F. Lu, M. J. Meziani, H. Li, G. Qi, B. Zhou, B. A. Harruff, F. Kermarrec and Y.-P. Sun, Chem. Commun., 2009, 3774-3776.

37 S. N. Baker and G. A. Baker, Angew. Chem., Int. Ed., 2010, 49, 6726-6744.

38 X. Xu, R. Ray, Y. Gu, H. J. Ploehn, L. Gearheart, K. Raker and W. A. Scrivens, J. Am. Chem. Soc., 2004, 126, 12736-12737.

39 S. Hu, J. Liu, J. Yang, Y. Wang and S. Cao, J. Nanopart. Res., 2011, 13, 7247-7252.

40 H. Liu, T. Ye and C. Mao, Angew. Chem., Int. Ed., 2007, 46, 6473-6475.

41 L. Tian, D. Ghosh, W. Chen, S. Pradhan, X. Chang and S. Chen, Chem. Mater., 2009, 21, 2803-2809.

42 Y. Dong, J. Shao, C. Chen, H. Li, R. Wang, Y. Chi, X. Lin and G. Chen, Carbon, 2012, 50, 4738-4743.

43 S. Qu, X. Wang, Q. Lu, X. Liu and L. Wang, Angew. Chem., Int. Ed., 2012, 51, 12215-12218.

44 S. Liu, J. Tian, L. Wang, Y. Zhang, X. Qin, Y. Luo, A. M. Asiri, A. O. Al-Youbi and X. Sun, Adv. Mater., 2012, 24, 2037-2041.

45 W. Lu, X. Qin, S. Liu, G. Chang, Y. Zhang, Y. Luo, A. M. Asiri, A. O. Al-Youbi and X. Sun, Anal. Chem., 2012, 84, 5351-5357.

46 J. Zhou, Z. Sheng, H. Han, M. Zou and C. Li, Mater. Lett., 2012, 66, 222-224.

47 R. Vikneswaran, S. Ramesh and R. Yahya, Mater. Lett., 2014, 136, 179-182.

48 A. Prasannan and T. Imae, Ind. Eng. Chem. Res., 2013, 52, 15673-15678.

49 S. Wunder, F. Polzer, Y. Lu, Y. Mei and M. Ballauff, J. Phys. Chem. C, 2010, 114, 8814-8820. 